\title{
Management of Urinary Calculi in Pregnancy: A Review
}

\author{
SHALOM J. SRIRANGAM, M.D., ${ }^{1}$ B. HICKERTON, M.D., ${ }^{1}$ and B. VAN CLEYNENBREUGEL, M.D. ${ }^{2}$
}

\begin{abstract}
Nephrolithiasis during pregnancy can represent a clinical dilemma because of potential risks to both mother and fetus. While the incidence of symptomatic nephrolithiasis during pregnancy varies between 1 in 244 to 1 in 2000 pregnancies, the actual incidence is likely to be higher. A significant proportion of patients with asymptomatic renal calculi are detected incidentally in the nonpregnant population compared with pregnant women. Factors that contribute to the diagnostic challenges include anatomic and physiologic changes to the female urinary tract during pregnancy and the limitations on the use of ionizing radiation. The treatment of such patients requires a multidisciplinary team approach involving the urologist, obstetrician, and radiologist. The potential hazards of intervention (either surgical or medical) and anesthesia need to be considered carefully.
\end{abstract}

\section{INTRODUCTION}

$\mathbf{N}^{\mathrm{i}}$ EPHROLITHIASIS in the pregnant patient can be a clinical dilemma because of potential risks to both mother and fetus. The incidence of symptomatic nephrolithiasis during pregnancy varies between 1 in 244 and 1 in 2000 pregnancies. The actual incidence, however, is likely to be higher because a significant proportion of patients have asymptomatic renal calculi that are detected incidentally in the nonpregnant population when compared with pregnant women. ${ }^{1-3}$

\section{DIAGNOSIS}

Diagnostic challenges occur because of such factors as anatomic and physiologic changes to the female urinary tract during pregnancy and the limitations on the use of ionizing radiation.

Anatomic alterations in the urinary tract during pregnancy

Normal anatomic changes within the urinary tract of the pregnant patient may not only predispose to calculi formation but may also pose a diagnostic challenge. Physiologic hydronephrosis can occur in $90 \%$ of right kidneys and up to $67 \%$ of left kidneys during pregnancy. ${ }^{4}$ The predominance of right upper tract dilation compared with the left may be caused by a combination of various factors including preferential compression of the right ureter because of uterine dextrorotation and protection of the left ureter by the gas-filled sigmoid colon. It is not uncommon for some pregnant women to experience greater pain relief when placed in the left lateral position. ${ }^{5}$

The mechanical theory (compression of the ureters by the gravid uterus and ovarian vein plexus) is likely to be the most significant cause of dilation. ${ }^{6}$ This is supported by the fact that ureteral dilation is absent below the pelvic brim and also in patients with a pelvic kidney or those who have previously undergone urinary diversion. ${ }^{5,7,8}$ Nulliparous patients have demonstrated a higher incidence of hydronephrosis in some studies presumably because of a better preserved abdominal musculature tone, which results in a greater degree of ureteral compression. 5,9

The hormonal theory postulates that circulating progesterone may influence smooth muscle dilation and thereby result in reduced ureteral peristalsis and increased dilation. ${ }^{10}$ While hormonal factors may contribute to the early development of gestational hydronephrosis, which is usually evident between 6 and 10 weeks of gestation, mechanical factors remain the major cause. Therefore, ureteral obstruction, dilation, and urinary stasis may aid aggregation of stone microconstituents, ultimately resulting in stone formation. Furthermore, it may be difficult to distinguish typically asymptomatic physiologic hydronephrosis from pathologic hydronephrosis using radiologic techniques.

\footnotetext{
${ }^{1}$ Department of Urology, Stepping Hill Hospital, Stockport, United Kingdom.

${ }^{2}$ Department of Urology, University Hospital Gasthuisberg, Katholieke Universiteit Leuven, Leuven, Belgium.
} 
Physiologic alterations in the urinary tract during pregnancy

An increase in cardiac output in combination with a decrease in renal vascular resistance results in significant elevations in both glomerular filtration rate (GFR) and renal plasma flow (RPF). By the second trimester, GFR and RPF can increase by $40 \%$ to $65 \%$ and $50 \%$ to $85 \%$, respectively. ${ }^{11}$ Subsequently, pregnancy is associated with an elevated creatinine clearance (by up to 50\%); lowered serum creatinine and urea levels; and higher renal filtration rate of glucose, sodium, calcium, and uric acid (potential stone formation promoters), as well as citrate, magnesium, and glycosaminoglycans (stone formation inhibitors). ${ }^{12}$ These physiologic changes may significantly alter the risk of stone formation and will need to be carefully considered in patients undergoing surgery under anesthesia, and affect those taking medications subjected to renal clearance.

Other nonrenal physiologic changes, while not directly influencing stone formation, may be relevant in the treatment of the pregnant patient, especially if invasive intervention is required: Cardiac-increased cardiac output by up to $50 \%$; respiratory-decreased functional reserve capacity and increased oxygen consumption (therefore increased minute ventilation); acid-base balance-relative respiratory alkalosis and a compensatory increase in renal bicarbonate excretion; and hematologic - physiologic anemia of pregnancy and hypercoagulable state with increased risk of deep-vein thrombosis.

\section{Excretion of stone-related substrates during pregnancy}

Gestational hypercalciuria is secondary to a combination of an increased GFR and therefore increased filtered load of calcium, suppression of parathyroid hormone (causing suppression of tubular calcium resorption), and increased levels of placental 1,25-dihydroxycholecalciferol (which promotes intestinal reabsorption of calcium as well as release of calcium from bone). Serum calcium levels, however, remain unaltered. Similarly, urinary excretion of uric acid and oxalate (both agents known to encourage stone formation) increases in pregnant patients. The cause is not accurately known but is likely to be multifactorial, including increased renal filtration, and dietary and fetal factors. ${ }^{13,14}$

Even in the presence of conditions that facilitate crystal precipitation and growth, pregnancy is not associated with an increased incidence of urolithiasis. ${ }^{15,16}$ This is most likely because of the limited duration of pregnancy and the significantly increased urinary excretion of substances known to retard stone formation by inhibition of crystal growth and aggregation, such as citrate, magnesium, and glycosaminogycans. ${ }^{12-14}$

\section{Demographics}

Urolithiasis in pregnant women has a similar incidence to that in nonpregnant women of a comparable age. ${ }^{16,17}$ The average age at presentation is 27 years. ${ }^{1,18}$ Between $80 \%$ and $90 \%$ of these pregnant women are in their second or third trimester. Stone formation risk is roughly three times higher in multiparous compared with primiparous women. ${ }^{16-19}$ In addition, patients are more likely to be white and have a history of renal disease and hypertension. ${ }^{2}$
While previously known stone formers have a generally higher chance of recurrent stones, this risk does not appear to manifest itself during pregnancy. Residents in the "stone belt" formed by the southern United States still have a higher incidence of urolithiasis during pregnancy. ${ }^{20}$ Either side may be affected equally, although gestational hydronephrosis is more common on the right side. Ureteral stones are encountered twice as often as renal calculi. ${ }^{18,21}$ Between $24 \%$ and $30 \%$ of women have a previous history of stone disease. ${ }^{18,22}$

\section{Clinical presentation}

Two points are worth noting when considering presenting symptoms in the pregnant woman with stones. First, while a patient may complain of classic and unmistakable symptoms of ureteral calculi, concomitant nebulous complaints such as abdominal and visceral discomfort may confuse the clinical picture. Second, the anatomic and physiologic changes occurring within pregnancy may, of themselves, give rise to abdominal/flank pain, nausea, and lower urinary-tract symptoms. A high index of suspicion is mandatory to effect a prompt and correct diagnosis of urolithiasis.

Flank or abdominal pain is the most common symptom; it occurs in $85 \%$ to $100 \%$ of patients. $1,7,16,18,20,21,23,24$ Patients with stone disease often complain of more severe pain, necessitating more analgesia compared with those with noncalculous pyelonephritis. Inflammatory pathologies that affect the peritoneal contents, such as appendicitis and diverticulitis, may mimic pain secondary to stone disease. In one series, $28 \%$ of patients initially received an incorrect diagnosis, with appendicitis, diverticulitis, and placental abruption the most common incorrect diagnoses. ${ }^{18}$

Frank hematuria is reported in $15 \%$ to $30 \%$ of proven cases, and microscopic hematuria can be detected in $95 \%$ to $100 \%$ of cases, although urinalysis may need to be repeated up to three times. ${ }^{18,22}$ Hematuria may also be secondary to congenital anomalies, tumors, renovascular complications, and endometriosis. $^{25}$

Lower urinary-tract symptoms may suggest a lower ureteral stone or infection. Nonspecific symptoms, including nausea and vomiting, are present to a varying degree. Other modes of presentation include urinary-tract infection (UTI), pre-eclampsia, and premature onset or arrest of labor. ${ }^{2,7,24,26}$ Effective treatment or spontaneous passage of stone usually results in alleviation of the obstetric emergency.

\section{Laboratory tests}

Dipstick analysis of a midstream specimen of urine is mandatory to assess hematuria (almost invariably present in urolithiasis), pyuria (may suggest concomitant infection), and $\mathrm{pH}$ (if greater than 7, it may signal the presence of infection stones with an urea-splitting organism; if less than 5, it may be associated with a uric acid stone).

Urine culture and sensitivity may identify the underlying pathogen. Standard serum tests should include complete blood count (to assess anemia and existence of systemic infection); potassium (decreased in renal tubular acidosis, increased in renal failure); urea and creatinine (usually the same or $25 \%$ less than in nonpregnant women but may be elevated in renal failure); bicarbonate (decreased in renal tubular acidosis); calcium 
(if elevated, may increase stone formation risk); and uric acid (increased levels predispose to both uric acid and calcium stones).

In the report by Stothers and Lee, ${ }^{18}$ dipstick or frank hematuria was noted in more than $95 \%$ of patients, pyuria in $42 \%$, and uropathogens-positive urine culture in $24 \%$.

Stones passed spontaneously or surgically retrieved should be retained and sent for stone analysis. Metabolic studies in the form of 24-hour urine collection (for measurement of urine volume and urinary concentrations of sodium, potassium, calcium, oxalate, phosphate, uric acid, citrate, and magnesium) are recommended before pregnancy in any patient at high risk of stone recurrence. Because of the physiologic and dietary alterations that accompany pregnancy, however, such investigations ought to be postponed until after delivery.

\section{RADIOLOGIC DIAGNOSIS}

The accurate diagnosis of urinary stone disease ideally necessitates radiologic evaluation using ionizing radiation. The most important factor remains the risk of radiation exposure to the fetus, but often the perception of risk is greater than the risk itself. ${ }^{27}$ Furthermore, inaccurate, missed, or delayed diagnosis may represent a more significant risk to the patient than the radiation risk.

A basic understanding of theoretical effects of ionizing radiation to the fetus is essential when counseling pregnant patients. Studies that involve the survivors of the Nagasaki and Hiroshima atomic bombs, as well as the Chernobyl nuclear reactor accident, have resulted in the classification of fetal effects into four categories, ${ }^{28,29}$ The categories are: intrauterine fetal death, fetal malformation, disturbance of growth and development, and mutagenic and carcinogenic effects.

The risk was also critically dependent on fetal gestational age and radiation dosage. ${ }^{30}$ Radiation effects can be considered as:

1. Deterministic. Effects become more severe with radiation dose increases. There is a dose threshold for an observed clinical effect (eg, death, growth retardation, and malformations):

- Preimplantation to week 3 gestation: Embryo most sensitive and likely to result in fetal death.
- Week 3 to week 10: Period of organogenesis and therefore growth malformations most likely.

- Week 8 to week 15: Risk of fetal mental retardation. Fortunately, first-trimester presentation of urolithiasis is rare.

2. Stochastic. The probability, not the severity, of the effect increases with dose, and no threshold is believed to exist. These effects are commonly believed to affect the fetus in later pregnancy (eg, cancer and genetic effects).

- Previous reports have suggested that radiation exposure in utero may result in a 1.3- to 2-fold increased risk of the development of childhood cancers, such as leukemia and other solid tumors. ${ }^{30-33}$ Other studies, however, have contradicted these findings, demonstrating no significantly elevated risk after exposure to either diagnostic radiation or the Hiroshima atomic bomb. ${ }^{34,35}$ Heritable genetic effects caused by ionizing radiation are difficult to quantify, given the high background rate of spontaneous mutations. At the low-level radiation doses involved in diagnostic radiology, however, it is unlikely that these result in significant inheritable genetic mutations. ${ }^{36}$ The National Radiological Protection Board (NRPB) concludes that the majority of radiologic and nuclear medicine procedures in an individual pregnancy present no substantial hazard and carry a risk of less than about 1 in 5000 for fatal childhood cancers ( 1 in 33,000 per mGy) and less than 1 in 10,000 for induced inheritable diseases ( 1 in 40,000 per $\mathrm{mGy}$ ). ${ }^{37}$

The delivered fetal dose for each procedure does not remain constant but varies according to the precise technique used and maternal body configuration. Fetal exposures of less than 50 mGy have not been reported to cause fetal growth or congenital defects (although this is by no means impossible), and most diagnostic procedures use doses well below this threshold. ${ }^{38}$ Fetal doses for common diagnostic procedures are given in Table 1.

The American College of Obstetricians and Gynecologists recommends that "Women should be counseled that the X-ray exposure from a single diagnostic procedure does not result in harmful effects." Specifically, exposure to less than $50 \mathrm{mGy}$ has not been associated with an increase in fetal anomalies or pregnancy loss. 39

Table 1. Fetal Doses for Common Diagnostic Procedures

\begin{tabular}{lcc}
\hline & \multicolumn{2}{c}{ Fetal dose $(m G y)$} \\
\cline { 2 - 3 } Procedure & Mean & Maximum \\
\hline Ultrasonography & \multicolumn{2}{c}{ No known biologic effects } \\
MRI (<1.5 Tesla) & No known biologic effects \\
Abdominal or KUB radiography & 1.4 & 4.2 \\
Intravenous urography & 1.7 & 10 \\
Renal tract CT & 8.0 & 49 \\
99mTc renal scan (MAG3 or DTPA) & 0.2 & 4.0 \\
\hline
\end{tabular}

MRI = magnetic resonance imaging; KUB = kidneys, ureters, bladder; $\mathrm{CT}=$ computed tomography; $\mathrm{Tc}=$ technetium; $\mathrm{MAG}=$ mercaptoacetyltriglycine; DTPA $=$ diethyl triamine pentaacetic acid. 


\section{Ultrasonography}

Ultrasonographic assessment of the urinary tract is the first investigation for all pregnant women when there is a suspicion of stone disease. The imaging mode operates at acoustic outputs, without any considerable rise in tissue temperature, and no harmful effects have been documented after years of use. Doppler ultrasonography (US) does have the theoretical potential to induce temperature rises, but this has not been a significant clinical finding. Real-time US demonstrates the renal parenchyma, pelvicaliceal system, dilated ureter, and, occasionally, the offending calculus without fetal radiation exposure and is therefore the primary diagnostic modality of choice.

US does, however, have a number of important disadvantages. First, the sensitivity of standard US in confirming urolithiasis varies considerably between $34 \%$ and $86 \% .^{18,19,40}$ Second, it is highly nonspecific and may be unable to differentiate between ureteral obstruction secondary to calculi and physiologic hydronephrosis. Ureteral dilation below the level of the pelvic brim/iliac artery is, however, not seen in the latter, and its presence must alert the investigator to the possibility of a lower ureteral stone. ${ }^{41}$

Transvaginal US is well tolerated and quick and has been shown to be effective in the detection of distal ureteral stones. ${ }^{42}$ Other modifications have been investigated to increase the accuracy of standard US. Doppler-assisted measurement of the resistive index (RI) (peak systolic velocity of intrarenal blood flow minus the end-diastolic velocity divided by the peak systolic velocity) has shown some promise in pregnancy. The RI does not appear to be affected by the nonobstructive physiologic obstruction of pregnancy.

Shokeir and colleagues ${ }^{43,44}$ have shown that an RI of 0.70 (sensitivity 45\%; specificity 91\%; accuracy $87 \%$ ) and, more importantly, a change in RI $(\Delta \mathrm{RI})$ of 0.06 (sensitivity $95 \%$; specificity $100 \%$; accuracy $99 \%$ ) may have a valuable role in the diagnosis of acute unilateral ureteral obstruction. As a single modality, RI may have certain limitations, and larger studies are needed. Renal disease, nonsteroidal anti-inflammatory drugs (NSAIDs), and early (less than 6 hours) and delayed (more than 48 hours) measurement may result in decreased sensitivity of RI in the diagnosis of obstruction. ${ }^{44}$

In a study that compared the value of US and renography in pregnant women with hydronephrosis, a renal pelvic diameter of less than $17 \mathrm{~mm}$ in asymptomatic patients effectively excluded the diagnosis of ureteral calculi. ${ }^{45}$ The presence of ureteral jets on real-time US or Doppler US can exclude complete ureteral obstruction in $80.4 \%$ to $100 \%$ of cases but requires a skilled sonographer. ${ }^{46-48}$

\section{Intravenous urography (IVU)}

Lee and Stothers ${ }^{18}$ reported that an IVU demonstrated calculi in 16 of 17 patients using a limited protocol. Irving and Burgess $^{49}$ reported 14 of 15 cases of correct diagnosis and concluded that IVU was safe and accurate in pregnancy. Urography should be considered after adequate time has elapsed to allow spontaneous elimination of calculi. Persistent fever after 48 hours of antibiotic therapy, rising serum urea and creatinine levels, US hydronephrosis, and persistent vomiting that results in dehydration are all indications for a limited IVU. ${ }^{23}$
The IVU is effective in providing anatomic and functional/excretory information and will verify site and extent of obstruction. The main concern related to IVU, however, is the potential adverse effects on the fetus of intravenous contrast media and ionizing radiation. Although a small proportion of iodinated contrast material is known to cross the placenta, no significant teratogenic or mutagenic effects have been demonstrated. ${ }^{50}$ Iodinated contrast exposure in later pregnancy has been shown to suppress fetal thyroid function, and neonates must be screened for hypothyroidism within the first week of life. ${ }^{50}$

If IVU is used, we suggest a limited sequence IVU (scout, 30 minutes after contrast injection, with or without delayed film at 2 hours), which results in a fetal radiation dose delivery of $0.5 \mathrm{mGy}$, far below the $5 \mathrm{mGy}$ safety margin. Fetal radiation can be further reduced by decreasing exposure times, using tight collimation, low voltages $(60-70 \mathrm{kV})$, maximal fetal shielding, and prone patient position. ${ }^{16}$ While ionizing radiation is best avoided, the maternal risk from delayed diagnosis must be balanced against potential risks to the fetus.

\section{Isotope renography}

Some investigators have advocated the use of nuclear medicine renography, rather than IVU, because the fetal radiation dose is one tenth the dosage delivered in IVU. ${ }^{21,51,52}$ Isotope renography will demonstrate drainage or confirm ureteral obstruction, but it lacks the anatomic information provided by IVU. The fetal dose can be further decreased by maintaining a high maternal oral fluid intake and encouraging frequent voiding to reduce isotope dwell time within the maternal bladder.

\section{$M R I$}

A heavily T2-weighted pulse sequence MRI with intravenous gadolinium has emerged as an attractive alternative to IVU, with many investigators reporting a comparable accuracy rate of $93 \%$ to $100 \%$ in the detection of pathologic ureteral obstruction. ${ }^{52-54}$ MRI uses electromagnetic radio waves rather than ionizing radiation, and no harmful effects to the patient or fetus have been reported. ${ }^{55,56}$ Because the experience with gadolinium is limited, especially during the first trimester, the NRPB recommends avoiding MRI in the first trimester. No adverse effects of gadolinium to the fetus, however, have been reported in pregnancy, and its use may be considered after full discussions with the patient. ${ }^{50}$

Although MRI does not visualize ureteral calculi, many salient features may suggest the presence of obstructing calculi. Stones appear as signal voids overlying the high signal of urine within a dilated ureter. ${ }^{54}$ The presence of a standing column of urine below the level of the pelvic brim, in addition to proximal ureteral dilation, is suggestive of an obstructing distal ureteral calculus ("double kink sign"). ${ }^{54}$ Other MRI features that suggest pathologic rather than physiologic hydronephrosis include an "unusual" site of obstruction (such as the pelvoureteral junction or vesicoureteral junction), an abrupt ending of the ureter (rather than a smooth taper at the level of the pelvic brim), and perinephric or periureteral edema.

Other benefits of MRI include the ability to detect nonurinary tract pathology (eg, appendicitis, ovarian torsion), characterize renal masses, and produce good image quality in spite of 
coexisting renal impairment. Drawbacks of MRI include a lack of a distinct signal from the calculi, limited availability, and interference with metal objects. In addition, MRI is time consuming and expensive and can produce a sense of claustrophobia. In spite of this, it is our belief that MRI is a useful, safe, and effective tool to aid the second-line assessment of the pregnant patient with suspected urolithiasis.

\section{$C T$}

Unenhanced CT has a detection rate approaching $100 \%$ for urinary-tract calculi, but at the expense of higher fetal radiation. Fetal exposure may be reduced by using narrow collimation and faster image acquisition, but $\mathrm{CT}$ is best avoided in routine use. It may have a limited role in the clarification of a suspected renal mass. ${ }^{57}$

\section{TREATMENT}

Although randomized studies in this field do not exist, the majority of symptomatic ureteral stones in pregnancy pass spontaneously, caused in part by the normally dilated upper urinary tract during pregnancy. Many series have constantly demonstrated a $64 \%$ to $84 \%$ spontaneous stone passage rate with conservative therapy. ${ }^{1,18,58}$ Of the remaining stones, Stothers ${ }^{18}$ reported that nearly half of these were passed in the postpartum period. Horowitz and Schmidt ${ }^{23}$ coined the phrase "expectant therapy for the expectant mother," because the guiding principle remains to minimize risk to the patient and fetus. Conservative treatment, which requires close communication between the urologist and obstetrician, includes hydration (oral or intravenous), analgesia, antibiotics (if infection present), antiemetics, rest, and routine sieving of urine. Approximately one third of patients treated in this way will have multiple admissions for fetal monitoring and intravenous hydration, although this is not an indication for surgery. The indications for active intervention will be discussed.

\section{Medical treatment}

Pharmacotherapy, in conjunction with expectant therapy, has a restricted role because most drugs used in the management of renal colic are contraindicated in gestation. Effective drugs that have been used for long periods are preferable to new, lessstudied alternatives. To minimize fetal risk, drug doses at the lower end of the therapeutic range should be used. ${ }^{59}$

Analgesia. Opiates are the first-line choice during pregnancy, because most other analgesics have a teratogenic potential. Morphine and meperidine are considered safe in pregnancy as are oral agents such as codeine or oxycodone. ${ }^{60}$ The use of NSAIDS is contraindicated because of concern about increased risk of oligohydramnios, early spontaneous abortion, and cardiac malformations. Other studies have not confirmed these findings. ${ }^{61}$ While uncertainty exists, NSAIDS are discouraged throughout pregnancy.

For severe pain, patients should receive either a patient-controlled analgesia pump or epidural administration of narcotics. ${ }^{62}$ The use of continuous segmental block (T11 and L2) has been recommended and may influence spontaneous passage of stones. ${ }^{20}$ An epidural block may also reduce distal ureteral smooth muscle tone and aid stone passage. ${ }^{20,62}$ This is rarely used but can be administered if patients refuse intervention or if there is a lack of endourologic expertise or equipment.

Antibiotics. Approximately 50\% of pregnant women who have stones have associated infection, and vigorous antibiotic treatment is indicated. ${ }^{61}$ Most trials of antibiotics in pregnancy involve patients with pyelonephritis (without the presence of stones). Enterobacteriaceae (Escherichia coli, Klebsiella, Enterobacter) make up $90 \%$ of causative pathogens seen on urinalysis. ${ }^{63}$ Most antibiotics cross the placenta, and both maternal and fetal safety must be considered.

Antimicrobials considered safe in pregnancy with good longterm data include cephalosporins, penicillins, macrolides, and nitrofurantoin, and these will form the mainstay of treatment in women with urolithiasis and infection. All patients should be treated individually, with treatment based on culture results and microbiologist advice.

Expulsive therapy. While alpha-adrenoceptor blockers, calcium channel blockers, and, to a lesser extent, corticosteroids significantly enhance spontaneous stone passage, there are no data for their use in pregnant women because these drugs are contraindicated in pregnancy. ${ }^{64,65}$ Their routine use cannot be recommended.

\section{Active management}

Unfortunately, $15 \%$ to $30 \%$ of patients' stones will ultimately necessitate some form of active invasive intervention. Indications for intervention are largely based on individual patient factors but include uncontrolled pain, sepsis, obstruction of a solitary kidney, bilateral obstruction, obstetric complications (premature onset of labor, pre-eclampsia), and poor access to urology care/equipment. ${ }^{66}$

Preintervention counseling must make the patient aware of the nature of the proposed intervention, the potential risks to patient and fetus, alternative therapies, and local available expertise. The counseling must take into consideration patient wishes and the gestational age. It is also imperative that a multidisciplinary team approach be adopted, including urologist, obstetrician, anesthesiologist, and radiologist.

Percutaneous nephrostomy (PCN) drainage. Temporary diversion of urine via a PCN tube remains a tested option, especially if the patient presents with sepsis because of an obstructing stone and when excessive ureteral manipulation is best avoided. ${ }^{67-69}$ Insertion is usually performed by a radiologist under local anesthesia using US guidance and is successful in more than $90 \%$ of patients. ${ }^{70,71}$ PCN tube insertion in pregnancy has a number of desirable advantages. ${ }^{24,66,69}$ It is minimally invasive, provides immediate and effective decompression of the obstructed system, can be performed in patients with acute sepsis, and can be accomplished under local anesthesia without ionizing radiation. The procedure allows urine collection for culture and sensitivities, avoids ureteral manipulation and associated complications, establishes access for future percutaneous nephrolithotomy or stone dissolution therapy, and produces minimal lower urinary-tract symptoms. In addition, straightforward tube exchanges can be effected over a guidewire, and the procedure is more cost-effective than placement of ureteral stents.

In comparison with internal ureteral stents, however, complications of PCN tube insertion include discomfort or bleed- 
ing during insertion, bacterial colonization, dislodgement, tube blockage requiring intervention or changes, and physical and social aspects of dealing with an external apparatus. ${ }^{71} \mathrm{PCN}$, therefore, is an effective option that will stabilize the clinical situation and permit definitive treatment of stones in the postpartum period. To minimize the occurrence of adverse effects of an indwelling PCN tube, however, it is advisable to change the tube at 6- to 8-week intervals.

Ureteral stent insertion. Effective and rapid ureteral decompression by the retrograde (via cystoscopy) or antegrade (after percutaneous renal puncture) insertion of an indwelling ureteral Double-J stent has been the traditional method of treating pregnant women with obstructed renal systems. ${ }^{19,72,73}$ It is also possible to insert such retrograde stents under local anesthesia using US guidance rather than fluoroscopy. ${ }^{74}$ Limited fluoroscopy may only be used if an inability to advance the guidewire up the ureter is encountered. The stone can be dealt with definitively after delivery.

In comparison with PCN, nonpregnant patients with indwelling ureteral stents are significantly more likely to complain of irritative lower urinary-tract symptoms (LUTS), stentrelated pain, and decreased quality of life, although this has not been studied in pregnant patients. ${ }^{75}$ Other well-recognized potential complications of stents include manipulation of the urinary tract causing possible trauma to the ureter, a higher incidence of LUTS including hematuria, an increased risk of ascending UTIs, and stent encrustation causing blockage.

A potent combination of gestational hypercalciuria, hyperuricosuria, and infection results in a tendency toward rapid stent encrustation. ${ }^{19,72}$ Patients are advised to maintain a high oral fluid intake and restrict dietary calcium intake to minimize oc- currence of encrustation; ultimately, stents may have to be replaced every 6 to 8 weeks, resulting in further inconvenience and potential risks for the patient. ${ }^{19,66}$ For this reason, investigators have suggested that the preferred technique of choice remain PCN before 22 weeks' gestation and a ureteral stent in later pregnancy. ${ }^{19,76}$

Ureteroscopy. In the event of failure of conservative treatment, ureteroscopy with stone retrieval is now considered the procedure of choice, provided that the appropriate endourologic expertise and equipment are available. It is associated with a significant decrease in the length of hospital stay when compared with ureteral stenting. ${ }^{77}$ Smaller endoscopes $(7.5 \mathrm{~F}, 9 \mathrm{~F}$, or $11.5 \mathrm{~F}$ ) allow complete visualization of the ureter and renal pelvis, enabling accurate diagnosis and definitive management for urolithiasis.

Numerous small series have demonstrated ureteroscopy to be safe and effective in all stages of pregnancy with stone-free rates between $70 \%$ and $100 \% .{ }^{77-83}$ Concerns had previously persisted regarding technical difficulties because of the tortuous nature of the lower ureter from uterine compression, but the physiologic ureterohydronephrosis makes manipulation easier. Ureteral dilatation is therefore avoided.

Ureteroscopy (both rigid and flexible) may be performed under a general or spinal anesthesia or even sedation, with the patient in the modified dorsal lithotomy position. ${ }^{77,81,83}$ The majority of procedures can be performed without ionizing radiation under US guidance, with fluoroscopy only used in the event of failure to advance the guidewire. ${ }^{77,83}$

Stone fragmentation/retrieval via ureteroscopy has been performed using the holmium:yttrium-aluminum-garnet (YAG) laser, pulsed-dye laser, ballistic lithotriptor, ultrasonic lithotrip-

Table 2. Summary of Studies Using Ureteroscopy in Pregnancy

\begin{tabular}{|c|c|c|c|c|c|c|c|c|}
\hline & $\begin{array}{l}\text { Number of } \\
\text { patients }\end{array}$ & $\begin{array}{c}\text { Fluoroscopy } \\
\text { used? }\end{array}$ & $\begin{array}{c}\text { Intracorporeal } \\
\text { lithotripsy }\end{array}$ & Stone retrieval & $\begin{array}{c}\text { Stent } \\
\text { inserted? }\end{array}$ & $\begin{array}{l}\text { Which } \\
\text { trimester? }\end{array}$ & $\begin{array}{c}\text { Obstetric } \\
\text { complications }\end{array}$ & $\begin{array}{l}\text { Stone } \\
\text { free? }\end{array}$ \\
\hline Juan $2007^{78}$ & 3 & No & None & Basket & No & 3 & None & $3 / 3$ \\
\hline Akpinar $2006^{84}$ & 7 & No & Ho: YAG (6) & Basket & $5 / 7$ & $1,2,3$ & None & $6 / 7$ \\
\hline Khoo $2002^{70}$ & 2 & $\mathrm{~N} / \mathrm{S}$ & $\mathrm{N} / \mathrm{S}$ & $\mathrm{N} / \mathrm{S}$ & No & 3 & None & $2 / 2$ \\
\hline Yang $2002^{92}$ & 3 & No & EHL (1) & Basket (2) & No & 1,2 & None & $3 / 3$ \\
\hline Lemos $2002^{79}$ & 14 & $1 / 14$ & USL (2) & Basket (11) & $8 / 14$ & 2,3 & None & $13 / 13$ \\
\hline Lifshitz $2002^{80}$ & 6 & Yes & None & Basket (4) & $3 / 6$ & 2,3 & None & $4 / 4$ \\
\hline Watterson $2002^{81}$ & 8 & Yes & Ho:YAG & No & $4 / 9$ & $1,2,3$ & None & $7 / 9$ \\
\hline Butler $2000^{40}$ & 2 & $\mathrm{~N} / \mathrm{S}$ & Laser & $\mathrm{N} / \mathrm{S}$ & No & $\mathrm{N} / \mathrm{S}$ & None & $2 / 2$ \\
\hline Shokeir $1998^{82}$ & 10 & No & USL (2) & Basket (3) & $10 / 10$ & $\mathrm{~N} / \mathrm{S}$ & None & $5 / 8$ \\
\hline Parulkar $1998^{58}$ & 4 & Yes & None & Basket (4) & No & 2 & None & $4 / 4$ \\
\hline Lee $1997^{93}$ & 1 & $\mathrm{~N} / \mathrm{S}$ & None & Basket & No & $\mathrm{N} / \mathrm{S}$ & None & $1 / 1$ \\
\hline Scarpa $1996^{83}$ & 15 & No & $\begin{array}{l}\text { Pulsed dye (3) } \\
\text { Ho:YAG (3) } \\
\text { Pneumatic (2) }\end{array}$ & Basket (2) & $15 / 15$ & 2,3 & None & $10 / 13$ \\
\hline Carringer $1996^{94}$ & 4 & No & Pulsed dye (4) & No & No & 3 & None & $4 / 4$ \\
\hline Ulvik $1995^{77}$ & 24 & No & $\begin{array}{l}\text { USL (2) } \\
\text { Forceps x1 }\end{array}$ & Basket (13) & $7 / 24$ & $1,2,3$ & PUC & $13 / 13$ \\
\hline Denstedt $1992^{19}$ & 3 & Yes & None & Basket (3) & No & 3 & None & $3 / 3$ \\
\hline Vest $1990^{95}$ & 2 & $\mathrm{~N} / \mathrm{S}$ & None & Basket (2) & $2 / 2$ & 2 & None & $2 / 2$ \\
\hline Rodriguez $1988^{96}$ & 1 & No & None & Basket (1) & $1 / 1$ & 2 & None & $1 / 1$ \\
\hline Rittenberg $1988^{97}$ & 2 & No & None & Basket (1) & $1 / 1$ & 2,3 & None & $1 / 1$ \\
\hline
\end{tabular}

Ho:YAG = holmium:yttrium-aluminum-garnet; N/S = not specified; USL = ultrasound lithotripsy; EHL = electrohydraulic lithotripsy; PUC $=$ premature uterine contractions. 
tor, basket retrieval, and forceps crush. Although all have been shown to be safe and successful without any known complications, it is our belief that the holmium:YAG laser represents the safest modality for intracorporeal lithotripsy. ${ }^{81,84}$ The holmium:YAG laser has a large safety margin (penetration of less than $0.5 \mathrm{~mm}$ from tip of probe), is effective against all stone types, can be used in the rigid as well as flexible instrument, has very little periureteral thermal effect, and its use does not result in any energy transmission through the patient or fetus. ${ }^{81,84}$

Sound intensities generated by holmium:YAG lasers are greatly reduced compared with those produced by US and electrohydraulic probes, thus potentially reducing the risk of damage to the developing fetal hearing. ${ }^{85}$ Although there remains the theoretical risk of cyanide formation by the action of laser on uric acid stones, this has not been reported as a clinical problem and it is likely that any cyanide produced is removed by the irrigation fluid. ${ }^{13}$

Most stones may be removed using a tipless stone basket with minimal trauma to the already dilated ureter. Many other modalities of intracorporeal lithotripsy have been used, but there remain legitimate concerns regarding unrecognized fetal hazards. Because of the high peak pressures generated by electrohydraulic lithotripsy, there is a risk of injury to the fetus or premature labor. ${ }^{86}$

It is postulated that US-generated high-pitched noise may result in hearing injury to the fetus, but Karlsen and associates ${ }^{85}$ concluded that peak pressures emitted by intracorporeal lithotriptors are unlikely to damage fetal hearing. The rigid nature of the pneumatic probe restricts its use to the semirigid ureteroscope and may limit its usefulness in pregnancy. Unlike the holmium:YAG laser, which fragments all types of calculi, the pulsed-dye laser is ineffective against harder stones (eg, cystine). Fetal complications related to intracorporeal lithotripsy are theoretical and have not been reported in the medical literature, except in a few case reports.

Akpinar and colleagues ${ }^{84}$ recommend routine stent placement with a string for 72 hours after ureteroscopy to reduce pain and analgesic requirements. Routine ureteral stenting (Double-J stent or ureteral catheter) beyond a few days after surgery may be advisable in the presence of ureteral trauma, edema, confirmed preexisting infection/sepsis, bleeding, or the presence of residual stones/fragments.

Contraindications to ureteroscopy according to Biyani and Joyce $^{66}$ include stones larger than $1 \mathrm{~cm}$, multiple calculi, sepsis, transplanted kidney, inadequacy of ureteroscopic experience or instruments, and solitary kidney (relative contraindication).

All reports that investigated the role (effectiveness and safety) of ureteroscopy in pregnancy in the English medical literature during the last 20 years are summarized in Table 2.

Percutaneous nephrolithotomy (PCNL). Patients with an indwelling nephrostomy tube may proceed to PCNL after delivery, but PCNL is not advised during pregnancy. Although two case reports have described successful PCNL in early pregnancy, the necessity for general anesthesia, need for fluoroscopy, and prone position of the patient make this a hazardous procedure. ${ }^{87,88}$

Extracorporeal shockwave lithotripsy (SWL). SWL is contraindicated in pregnancy because of the effects of the shockwave on the fetus, potentially resulting in fetal death. ${ }^{89}$ There have, however, been reports of SWL treatment in young women with unrecognized early pregnancies, who went on to have an uncomplicated pregnancy and healthy babies..$^{90,91}$ Mandatory termination of pregnancy must therefore not be recommended in such instances.

Open surgery. Open surgery is not advised, except in the treatment of a symptomatic patient with sepsis who is not responding to other therapeutics options and when endourology expertise or equipment is not available. ${ }^{66,67}$ This is a rare occurrence.

\section{CONCLUSION}

Although uncommon, urolithiasis that occurs during pregnancy can pose a challenge to urologists, obstetricians, and radiologists. A high index of suspicion is required for a prompt and correct diagnosis. The health of the patient and the developing fetus is paramount when considering investigations and therapeutic options. In the absence of prospective studies, this remains an area of much debate. US is the primary radiologic investigation of choice, followed by either an MRI or limited IVU. Fortunately, conservative, supportive management will result in spontaneous stone passage in the majority of patients. Where intervention is necessary, advances in endourologic equipment and techniques suggest that ureteroscopy, with holmium:YAG laser lithotripsy, is likely to be the safest and most effective management choice.

\section{REFERENCES}

1. Lewis DF, Robichaux AG III, Jaekle RK, Marcum NG, Stedman CM. Urolithiasis in pregnancy. Diagnosis, management and pregnancy outcome. J Reprod Med 2003;48:28-32.

2. Swartz MA, Lydon-Rochelle MT, Simon D, Wright JL, Porter MP. Admission for nephrolithiasis in pregnancy and risk of adverse birth outcomes. Obstet Gynecol 2007;109:1099-1104.

3. Gorton E, Whitfield HN. Renal calculi in pregnancy. Br J Urol 1997;80 (suppl 1):4-9.

4. Peake SL, Roxburg hHB, Langlois SL. Ultrasonic assessment of hydronephrosis of pregnancy. Radiology 1983;146:167-170.

5. Roberts JA. Hydronephrosis of pregnancy. Urology 1976;8:1-4.

6. Rasmussen PE, Neilson FR. Hydronephrosis during pregnancy: A literature survey. Eur J Obstet Gynecology Reprod Biol 1988;27: 249-259.

7. Swanson SK, Heilman RL, Eversman WG. Urinary tract stones in pregnancy. Surg Clin North Am 1995;75:123-142.

8. Harrow BR, Sloane JA, Salhanick L. Etiology of the hydronephrosis of pregnancy. Surg Gynecol Obstet 1964;119:10421048.

9. Faúndes A, Brícola-Filho M, Pinto e Silva JL. Dilatation of the urinary tract during pregnancy: Proposal of a curve of maximal caliceal diameter by gestational age. Am J Obstet Gynecol 1998;178: 1082-1086.

10. Marchant DJ. Effects of pregnancy and progestational agents on the urinary tract. Am J Obstet Gynecol 1972;112:487-501.

11. Conrad KP, Lindheimer MD. Renal and cardiovascular alterations. In: Lindheimer MD, Roberts JM, Cunningham FG, eds. Chesley's Hypertensive Disorders in Pregnancy. 2nd ed. Stamford, Conn: Appleton and Lange;1999: pp 263-326. 
12. Lindheimer MD, Katz AI. The renal response to pregnancy. In: Brenner BM, Rector RC, eds. The Kidney. 2nd ed. Philadelphia; WB Saunders, 1981, pp 1762-1819.

13. Smith CL, Kristensen C, Davis M, Abraham PA. An evaluation of the physicochemical risk for renal stone disease in pregnancy. Clin Nephrol 2001;55:205-211.

14. Maikranz P, Holley JL, Parks JH, Lindheimer MD, Nakagawa Y, Coe FL. Gestational hypercalciuria causes pathological urine calcium oxalate supersaturations. Kidney Int 1989;36:108-113.

15. Harris RE, Dunnihoo DR. The incidence and significance of urinary calculi in pregnancy. Am J Obstet Gynecol 1967;99:237-241.

16. Drago JR, Rohner TJ Jr, Chez RA. Management of urinary calculi in pregnancy. Urology 1982;20:578-581.

17. Coe FL, Parks JH, Lindheimer MD. Nephrolithiasis during pregnancy. N Engl J Med 1978;298:324-326.

18. Stothers L, Lee LM. Renal colic in pregnancy. J Urol 1992;148: 1383-1387.

19. Denstedt JD, Razvi H. Management of urinary calculi during pregnancy. J Urol 1992;148:1072-1075.

20. Maikranz P, Coe FL, Parks J, Lindheimer MD. Nephrolithiasis in pregnancy. Am J Kidney Dis 1987;9:354-358.

21. Biyani CS, Joyce AD. Urolithiasis in pregnancy. I: Pathophysiology, fetal considerations and diagnosis. BJU Int 2002;89:811-818.

22. Jones WA, Correa RJ Jr, Ansell JS. Urolithiasis associated with pregnancy. J Urol 1979;122:333-335.

23. Horowitz E, Schmidt JD. Renal calculi in pregnancy. Clin Obstet Gynecol 1985;28:324-338.

24. Pais VM Jr, Payton AL, LaGrange CA. Urolithiasis in pregnancy. Urol Clin North Am 2007;34:43-52.

25. Waltzer WC. The urinary tract in pregnancy. J Urol 1981;125: 271-276.

26. Cope E. Obstructed labour due to vesical calculus. J Obstet Gynaecol Br Commonw 1961;68:476-478.

27. Ratnapalan S, Bona N, Chandra K, Koren G. Physicians' perceptions of teratogenic risk associated with radiography and CT during early pregnancy. AJR Am J Roentgenol 2004;182:1107-1109.

28. Yamazaki JN, Schull WJ. Perinatal loss and neurological abnormalities among children of the atomic bomb: Nagasaki and Hiroshima revisited, 1949 to 1989. JAMA 1990;264:605-609.

29. Castronovo FP. Teratogen update: Radiation and Chernobyl. Teratology 1999;60:100-106.

30. Brent RL. The effect of embryonic and fetal exposure to x-ray, microwaves, and ultrasound: Counseling the pregnant and nonpregnant patient about these risks. Semin Oncol 1989;16:347-368.

31. Stewart A. The carcinogenic effects of low-level radiation. A reappraisal of epidemiologist's methods and observations. Health Phys 1973;24:223-240.

32. Lilienfeld AM. Epidemiological studies of the leukemogenic effects of radiation. Yale J Biol Med 1966;39:143-164.

33. Stewart A, Kneale GW. Radiation dose effects in relation to obstetric X-rays and childhood cancers. Lancet 1970;1:1185.

34. Court Brown WM, Doll R, Hill RB. Incidence of leukaemia after exposure to diagnostic radiation in utero. Br Med J 1960;2:15391545.

35. Kato H. Mortality in children exposed to the A-bombs while in utero, 1945-1969. Am J Epidemiol 1971;93:435-442.

36. Brent RL. The effects of embryonic and fetal exposure to X-ray, microwaves, and ultrasound. Clin Obstet Gynecol 1983;26:484510.

37. NRPB. Diagnostic Medical Exposure - Advice on exposure to ionising radiation during pregnancy. Chilton, 1998.

38. Kinlen LJ, Acheson ED. Diagnostic irradiation, congenital malformations and spontaneous abortion. Br J Radiol 1968;41:648654.

39. American College of Obstetricians and Gynecologists Committee on Obstetric Practice. Guidelines for Diagnostic Imaging During
Pregnancy. ACOG Committee opinion no 158. Washington DC: ACOG, 1995.

40. Butler EL, Cox SM, Eberts EG, Cunningham FG. Symptomatic nephrolithiasis complicating pregnancy. Obstet Gynecol 2000;96: 753-756.

41. MacNeily AE, Goldenberg SL, Allen GJ, Ajzen SA, Cooperberg PL. Sonographic visualization of the ureter in pregnancy. J Urol 1991;146:298-301.

42. Laing FC, Benson CB, DiSalvo DN, Brown DL, Frates MC, Laoughlin KR. Distal ureteral calculi: Detection with vaginal US. Radiology 1994;192:545-548

43. Shokeir AA, Mahran MR, Abdulmaaboud M. Renal colic in pregnant women: Role of renal resistive index. Urology 2000;55:344347

44. Shokeir AA, Abdulmaaboud M. Resistive index in renal colic: A prospective study. BJU Int 1999;83:378-382.

45. Müller-Suur R, Tyden O. Evaluation of hydronephrosis in pregnancy using ultrasound and renography. Scand J Urol Nephrol 1985;19:267-273.

46. Deyoe LA, Cronan JJ, Breslaw BH, Ridlen MS. New techniques of ultrasound and color Doppler in the prospective evaluation of acute renal obstruction. Do they replace the intravenous urogram? Abdom Imaging 1995;20:58-63.

47. Geavlete P, Georgescu D, Cauni V, Nita G. Value of duplex Doppler ultrasonography in renal colic. Eur Urol 2002;41:71-78.

48. Asrat T, Roossin MC, Miller EI. Ultrasonographic detection of ureteral jets in normal pregnancy. Am J Obstet Gynecol 1998;178: 1194-1198.

49. Irving SO, Burgess NA. Managing severe loin pain in pregnancy. BJOG 2002;109:1025-1029.

50. Webb JA, Thomsen HS, Morcos SK. Members of Contrast Media Safety Committee of European Society of Urogenital Radiology (ESUR). The use of iodinated and gadolinium contrast media during pregnancy and lactation. Eur Radiol 2005;15:1234-1240.

51. Voigt R, Stoll W, Arndt J. [The value of radio-isotope investigations of the urinary tract for the diagnosis of urinary tract calculi during pregnancy.] (Ger) Geburtshilfe Frauenheilkd 1980;40:863867.

52. Spencer JA, Tomlinson AJ, Weston MJ, Lloyd SN. Early report: Comparision of breath-hold MR excretory urography, Doppler ultrasound and isotope renography in evaluation of symptomatic hydronephrosis in pregnancy. Clin Radiol 2000;55:446-453.

53. Roy C, Saussine C, Le Bras Y, Delepaul B, Jahn C, Steichen G, Jacqmin D, Chambron J. Assessment of painful ureterohydronephrosis during pregnancy by MR urography. Eur Radiol 1996; 6:334-338.

54. Spencer JA, Chahal R, Kelly A, Taylor K, Eardley I, Lloyd SN. Evaluation of painful hydronephrosis in pregnancy: Magnetic resonance urographic patterns in physiological dilatation versus calculous obstruction. J Urol 2004;171:256-260.

55. Nicklas AH, Baker ME. Imaging strategies in the pregnant cancer patient. Semin Oncol 2000;27:623-632.

56. Schwartz JL, Crooks LE. NMR imaging produces no observable mutation or cytotoxicity in mammalian cells. AJR Am J Roentgenol 1982;139:583-585.

57. Loughlin KR. Urologic radiology during pregnancy. Urol Clin North Am 2007;34:23-26.

58. Parulkar BG, Hopkins TB, Wollin MR, Howard PJ Jr, Lal A. Renal colic during pregnancy: A case for conservative treatment. J Urol 1998;159:365-368.

59. Shrim A, Garcia-Bournissen F, Koren G. Pharmaceutical agents and pregnancy in urology practice. Urol Clin North Am 2007;34: 27-33.

60. Briggs GG, Freeman RK, Yaffe SJ, et al. Drugs in Pregnancy and Lactation 5th ed. Baltimore: Williams and Wilkins, 1998, pp 672674, 746-748. 
61. Butler EL, Cox SM, Eberts EG, Cunningham FG. Symptomatic nephrolithiasis complicating pregnancy. Obstet Gynecol 2000;96: 753-756.

62. Ready LB, Johnson ES. Epidural block for treatment of renal colic during pregnancy. Can Anaesth Soc J 1981;28:77-79.

63. Macejko AM, Schaeffer AJ. Asymptomatic bacteriuria and symptomatic urinary tract infections during pregnancy. Urol Clin North Am 2007;34:35-42.

64. Singh A, Alter HJ, Littlepage A. A systematic review of medical therapy to facilitate passage of ureteral calculi. Ann Emerg Med 2007;50:552-563.

65. Porpiglia F, Vaccino D, Billia M, et al. Corticosteroids and tamsulosin in the medical expulsive therapy for symptomatic distal ureter stones: Single drug or association? Eur Urol 2006;50:339-344.

66. Biyani CS, Joyce AD. Urolithiasis in pregnancy. II: Management. BJU Int 2002;89:819-823.

67. Meares EM Jr. Urologic surgery during pregnancy. Clin Obstet Gynecol 1978;21:907-920.

68. Kavoussi LR, Albala DM, Basler JW, Apte S, Clayman RV. Percutaneous management of urolithiasis during pregnancy. J Urol 1992;148:1069-1071.

69. Pearle MS, Pierce HL, Miller GL, et al. Optimal method of urgent decompression of the collecting system for obstruction and infection due to ureteral calculi. J Urol 1998;160:1260-1264.

70. Khoo L, Anson K, Patel U. Success and short-term complication rates of percutaneous nephrostomy during pregnancy. J Vasc Interv Radiol 2004;15:1469-1473.

71. Stables DP. Percutaneous nephrostomy: Techniques, indications, and results. Urol Clin North Am 1982;9:15-29.

72. Loughlin KR, Bailey RB Jr. Internal ureteral stents for conservative management of ureteral calculi during pregnancy. $\mathrm{N}$ Engl $\mathrm{J}$ Med 1986;315:1647-1649.

73. Delakas D, Karyotis I, Loumbakis P, Daskalopoulos G, Kazanis J, Cranidis A. Ureteral drainage by double-J-catheters during pregnancy. Clin Exp Obstet Gynecol 2000;27:200-202.

74. Jarrard DJ, Gerber GS, Lyon ES. Management of acute ureteral obstruction in pregnancy utilizing ultrasound-guided placement of ureteral stents. Urology 1993;42:263-268.

75. Mokhmalji H, Braun PM, Martinez Portillo FJ, Siegsmund M, Alken P, Köhrmann KY. Percutaneous nephrostomy versus ureteral stents for diversion of hydronephrosis caused by stones: A prospective, randomized clinical trial. J Urol 2001;165:1088-1092.

76. McAleer SJ, Loughlin KR. Nephrolithiasis and pregnancy. Curr Opin Urol 2004;14:123-127.

77. Ulvik NM, Bakke A, Hoisaeter PA. Ureteroscopy in pregnancy. J Urol 1995;154:1660-1663.

78. Juan YS, Wu WJ, Chuang SM, Wang Cj, Shen JT, Long CY, Huang $\mathrm{CH}$. Management of symptomatic urolithiasis during pregnancy. Kaohsiung J Med Sci 2007;23:241-246.

79. Lemos GC, El Hayek OR, Apezzato M. Rigid ureteroscopy for diagnosis and treatment of ureteral calculi during pregnancy. Int Braz J Urol 2002;28:311-316.

80. Lifshitz DA, Lingeman JE. Ureteroscopy as a first-line intervention for ureteral calculi in pregnancy. J Endourol 2002;16:19-22.

81. Watterson JD, Girvan AE, Beiko DT, Nott L, Wollin TA, Razvi H, Denstedt JD. Ureteroscopy and holmium:YAG laser lithotripsy: An emerging definitive management strategy for symptomatic ureteral calculi in pregnancy. Urology 2002;60:383-387.

82. Shokeir AA, Mutabagani H. Rigid ureteroscopy in pregnant women. Br J Urol 1998;81:678-681.

83. Scarpa RM, De Lisa A, Usai E. Diagnosis and treatment of ureteral calculi during pregnancy with rigid ureteroscopes. J Urol 1996; 155:875-877.

84. Akpinar H, Tüfek I, Alici B, Kural AR. Ureteroscopy and holmium laser lithotripsy in pregnancy: Stents must be used postoperatively. J Endourol 2006;20:107-110.
85. Karlsen SJ, Bull-Njaa T, Krokstad A. Measurement of sound emission by endoscopic lithotriptors: An in vitro study and theoretical estimation of risk of hearing loss in a fetus. J Endourol 2001; 15:821-826.

86. Evans HJ, Wollins TA. The management of urinary calculi in pregnancy. Curr Opin Urol 2001;11:379-384.

87. Shah A, Chandak P, Tiptaft R, Glass J, Dasgupta P. Percutaneous nephrolithotomy in early pregnancy. Int J Clin Pract 2004;58: 809-810.

88. Tóth C, Tóth G, Varga A, Flaskó T, Salah MA. Percutaneous nephrolithotomy in early pregnancy. Int Urol Nephrol 2005;37:1-3.

89. Streem SB. Contemporary clinical practice of shockwave lithotripsy: A reevaluation of contraindications. J Urol 1997;157;1197-1203.

90. Asgari MA, Safarinejad MR, Hosseini SJ, Dadkhah F. Extracorporeal shock wave lithotripsy of renal calculi during early pregnancy. BJU Int 1999;84:615-617.

91. Deliveliotis CH, Argyropoulus B, Chrisofos M, Dimopoulos CA, Shockwave lithotripsy in unrecognized pregnancy: Interruption or continuation? J Endourol 2001;15:787-788.

92. Yang CH, Chan PH, La SK, Chang HC, Chiu B, Lin HM, Sheu MH. Urolithiasis in pregnancy. J Chin Med Assoc 2004;67:625-628.

93. Lee SJ, Rho SK, Lee CH, Chang SG, Kim JI. Management of urinary calculi in pregnant women. J Korean Med Sci 1997;12:40-43.

94. Carringer M, Swartz R, Johansson JE. Management of ureteric calculi during pregnancy by ureteroscopy and laser lithotripsy. Br J Urol 1996;77:17-20.

95. Vest JM, Warden SS. Ureteroscopic stone manipulation during pregnancy. Urology 1990;35:250-252.

96. Rodriguez PN, Klein AS. Management of urolithiasis during pregnancy. Surg Gynecol Obstet 1998;166:103-106.

97. Rittenberg MH, Bagley DH. Ureteroscopic diagnosis and treatment of urinary calculi during pregnancy. Urology 1988;32:427-428.

Address reprint requests to: Dr. Shalom Srirangam Stepping Hill Hospital 93 Cromwell Road Stretford Manchester, United Kingdom M32 8QL

E-mail: sjsrirangam@yahoo.co.uk

\section{ABBREVIATIONS USED}

$$
\begin{aligned}
\mathrm{CT} & =\text { computed tomography } \\
\mathrm{GFR} & =\text { glomerular filtration rate } \\
\text { LUTS } & =\text { lower urinary-tract symptoms } \\
\mathrm{MRI} & =\text { magnetic resonance imaging } \\
\text { NRPB } & =\text { National Radiological Protection Board } \\
\text { NSAIDs } & =\text { nonsteroidal anti-inflammatory drugs } \\
\mathrm{PCN} & =\text { percutaneous nephrostomy } \\
\text { PCNL } & =\text { percutaneous nephrolithotomy } \\
\text { RI } & =\text { resistive index } \\
\text { RPF } & =\text { renal plasma flow } \\
\text { SWL } & =\text { shockwave lithotripsy } \\
\mathrm{US} & =\text { ultrasonography } \\
\mathrm{UTI} & =\text { urinary-tract infection } \\
\text { YAG } & =\text { yttrium-aluminum-garnet }
\end{aligned}
$$


